\title{
EKSPLORASI TEKNOLOGI TEPAT GUNA DALAM PENANGKAPAN KAKAP PUTIH (Lates calcarifer) DI KABUPATEN MIMIKA
}

\author{
(EXPLORATION OF THE APPROPRLATE FISHING TECHNOLOGY FOR \\ BARRAMUNDI (Lates Calcarifer) FISHERIES IN MIMIKA REGENCY)
}

\author{
Domu Simbolon $^{1}, 2$, Ari Purbayanto ${ }^{2}$, Julia E. Astarini' ${ }^{2}$, dan Wesley Simanungkalit ${ }^{3}$ \\ Departemen Pemanfaatan Sumberdaya Perikanan \\ Fakultas Perikanan dan Ilmu Kelautan, Institut Pertanian Bogor
}

\begin{abstract}
Utilization level of barramundi in Mimika Regency waters tend to increase every years, because the kind of fish had the bigh economical value. This condition usually could be trigger to use the environmental unfriendly fishing technology for increasing the catches. Development of the appropriate fishing technology in Mimika waters must consider the maximum sustainable yield (MSY) of barramundi resources, social, and economic aspects of fisherman. The objectives of this research were to explore the MSY of barramundi resources, to determine the development opportunity of barramundi fisheries, to explore the appropriate fishing technology of barramundi, and to determine the development strategy of barramundi fishing technology in Mimika Regency waters. The research method used was survey through experimental fishing activitiy. Data were analyzed with bioeconomic model, multicriteria analysis, and analitical bierarchy process approaches. The estimated MSY of barramundi in Mimika waters was 8,348 tons/year, and fishing effort was 970,122 trips/year. Development opportunity at MSY condition was 6,807 tons/year while at MEY management was 6,553 tons/year. The appropriate fishing technology for Barramundi fisheries in Mimika Regency was gillnet and handlne, but gillnet was more adventage than handline. The gillnet becomes main priority for developing with a strategy of fisherman empowerment, and cooperative among stakeholders for improving catch and fishermen income.
\end{abstract}

Keywords: Barramundi, fishing technology, appropriate, Mimika Regency

\begin{abstract}
ABSTRAK
Tingkat pemanfaatan ikan kakap putih di peraian Kabupaten Mimika cenderung meningkat setiap tahun, karena jenis ikan ini memiliki nilai ekonomis yang tinggi. Kondisi ini biasanya menjadi pemicu untuk menggunakan teknologi penangkapan ikan yang tidak ramah lingkungan dalam meningkatkan hasil tangkapan. Pengembangan teknologi penangkapan ikan tepat guna di perairan Mimika harus mempertimbangkan potensi lestari ikan kakap putih, aspek sosial dan ekonomi nelayan. Tujuan penelitian ini adalah untuk mengeksplorasi potensi lestari SDI kakap putih, menentukan peluang pengembangan perikanan kakap putih, mengeksplorasi teknologi penangkapan ikan kakap putih yang tepat guna, dan menentukan strategi pengembangan dalam usaha penangkapan kakap putih di perairan Kabupaten Mimika. Metode penelitian yang digunakan adalah survei melalui kegiatan experimental fishing. Data dianalisis dengan pendekatan model bio-ekonomi, multicriteria analysis dan analitycal hierarchy process. Dugaan potensi lestari ikan kakap putih di perairan Mimika adalah 8.348 ton/tahun, dan upaya penangkapan optimum 970.122 trip/tahun. Peluang pengembangan pada kondisi pengelolaan MSY adalah 6,807 ton/tahun, sedangkan pada kondisi pengelolaan MEY 6.553 ton/tahun. Teknologi tepat guna dalam penangkapan kakap putih di perairan Mimika adalah jaring insang dan pancing ulur, tetapi jaring insang lebih menguntungkan dibandingkan pancing ulur. Jaring insang menjadi prioritas pertama untuk dikembangkan dengan melakukan strategi pembinaan nelayan, dan kerjasama antar pelaku untuk meningkatkan hasil tangkapan dan kesejahteraan nelayan.
\end{abstract}

Kata kunci: Kakap putih, teknologi penangkapan, tepat guna, Kabupaten Mimika

\section{PENDAHULUAN}

\subsection{Latar Belakang}

$\quad$ Kakap
$\begin{aligned} & \text { putih (Lates calcarifer) } \\ & \text { merupakan salah satu komoditas } \\ & \text { unggulan sebagai }\end{aligned}$ penyumbang
pendapatan asli daerah (PAD) yang
diharapkan oleh Pemerintah Kabupaten

Mimika dari bidang perikanan tangkap. Usaha penangkapan di perairan Mimika berusaha meningkatkan jumlah upaya penangkapan kakap putih karena harga ikannya yang cukup tinggi (Dinas Perikanan dan Kelautan Kab Mimika, 2006). Fenomena tersebut dapat mengancam kelestarian sumberdaya ikan apabila upaya penangkapan tidak

\footnotetext{
${ }^{1}$ Corresponding author

${ }^{2}$ Staf Departemen Pemanfaatan Sumberdaya Perikanan, FPIK - IPB

${ }^{3}$ Alumni Program Studi Teknologi Kelautan Pascasarjana IPB
} 
dikontrol sesuai dengan jumlah potensi lestari. Fauzi dan Anna (2002), menyatakan bahwa keberlanjutan merupakan kata kunci dalam pembangunan perikanan yang diharapkan dapat memperbaiki kondisi sumberdaya dan kesejahteraan masyarakat perikanan itu sendiri.

Sumberdaya ikan (SDI) dikategorikan sebagai sumberdaya yang dapat pulih, namun demikian tingkat pemanfaatan SDI yang berlebihan dapat menimbulkan permasalahan yang kompleks (Malanesia et al., 2007). Penentuan alokasi optimum upaya penangkapan dalam pemanfaatan SDI kakap putih di perairan Mimika membutuhkan data dan informasi yang akurat tentang potensi lestari, sehingga kelestarian SDI dan keberlanjutan usaha perikanan tetap terjamin.

Pemanfaatan sumberdaya ikan diharapkan dapat meningkatkan pendapatan nelayan, namun demikian bahwa penggunaan teknologi penangkapan harus sesuai (tepat guna) agar tidak mengancam kelestarian SDI itu sendiri. Jumlah alokasi unit penangkapan harus diatur agar tidak terjadi kelebihan tangkap, bahkan konflik sosial di antara nelayan (Simbolon, 2008). Peluang untuk menambah unit penangkapan dan penggunaan teknologi yang tidak ramah lingkungan dalam usaha penangkapan ikan kakap putih di perairan Mimika cukup besar karena harga ikan tersebut relatif tinggi.

Pemanfaatan potensi perikanan kakap putih di perairan Kabupaten Mimika belum dapat dilakukan secara optimal karena keterbatasan informasi dasar, terkait dengan jumlah potensi SDI, dan keragaan teknologi penangkapan. Berdasarkan studi pendahuluan, kendala lain yang ditemukan di lokasi penelitian adalah sarana dan prasarana usaha perikanan tangkap yang terbatas, armada penangkapan yang masih tergolong skala kecil, rantai pemasaran belum tertata baik, keterbatasan modal usaha, dan adopsi teknologi yang rendah. Untuk itu perlu dilakukan kajian yang sistematis untuk menentukan pola pengembangan perikanan kakap putih yang berkelanjutan, dengan mempertimbangkan aspek biologis, teknis, sosial, ekonomi dan lingkungan, agar tidak menimbulkan dampak negatif di masa mendatang.

\subsection{Tujuan Penelitian}

Tujuan penelitian ini adalah untuk (1) mengeksplorasi potensi lestari SDI kakap putih, (2) menentukan peluang pengembangan perikanan kakap putih, (3) mengeksplorasi teknologi penangkapan ikan kakap putih yang tepat guna, dan (4) menentukan strategi pengembangan dalam usaha penangkapan kakap putih di perairan Kabupaten Mimika.

\section{METODOLOGI}

\subsection{Waktu dan Lokasi Penelitian}

Penelitian ini dilaksanakan pada bulan Maret-Mei 2006 di perairan Kabupaten Mimika, Provinsi Papua.

\subsection{Metode Pengumpulan Data}

Penelitian ini dilakukan dengan menggunakan metode survei. Data yang dikumpulkan meliputi produksi dan upaya penangkapan, jumlah dan ukuran (size) ikan kakap putih yang tertangkap, biaya operasi penangkapan, dan harga ikan kakap putih. Data produksi dan upaya penangkapan selama tujuh tahun diperoleh dari Dinas Perikanan dan Kelautan Kab. Mimika.

Sampel kapal yang diamati ditentukan secara sengaja (purposive sampling), dengan pertimbangan bahwa kapal tersebut menangkap kakap putih dan layak operasi, serta ada izin/kesediaan pemilik kapal. Dengan pertimbangan tersebut, maka ditetapkan sampel kapal jaring insang dan pancing ulur masing-masing 10 unit. Data primer yang dikumpulkan dari sampel kapal meliputi jumlah dan ukuran panjang kakap putih yang tertangkap, jumlah anak buah kapal (ABK). Pada setiap trip operasi kapal sampel, ditimbang jumlah tangkapan total dan tangkapan kakap putih, lalu diambil sampel ikan kakap putih untuk diukur panjangnya. Sampel ikan diambil secara acak yang jumlahnya berkisar 5-10 ekor per trip tergantung variabilitas ukuran ikan.

Data biaya operasional, dan harga ikan kakap putih diperoleh dari hasil wawancara dan pengisian kuesioner oleh 20 responden, masing-masing 10 orang 
anak buah kapal (ABK) untuk mewakili unit penangkapan jaring insang, 5 orang ABK untuk mewakili unit penangkapan pancing ulur, dan 5 orang untuk mewakili pedagang pengumpul ikan. Responden ditentukan secara sengaja (purposive sampling), dengan pertimbangan bahwa responden bersedia dan memahami isi pertanyaan.

\subsection{Analisis Data}

\section{(1) Pendugaan potensi lestari dengan model bio-ekonomi}

Pendekatan bio-ekonomi merupakan salah satu alternatif pengelolaan yang dapat diterapkan dalam rangka meningkatkan pengusahaan sumberdaya secara berkelanjutan. Potensi lestari ikan kakap putih di perairan Kabupaten Mimika dianalisis dengan model Schaefer dan model Fox. Sebelum dilakukan analisis regresi untuk mengetahui hubungan antara CPUE dengan upaya penangkapan (effort), terlebih dahulu dilakukan standarisasi terhadap effort, karena jaring insang dan pancing ulur yang menangkap kakap putih di lokasi penelitian memiliki kemampuan tangkap (catchability) yang berbeda. Teknik standarisasi mengikuti prosedur yang dianjurkan Sparre \& Venema (1999).

1. Penentuan model yang menunjukkan hubungan antara CPUE dengan effort adalah :

$$
C P U E=h / E=a-b E
$$

2. Pendugaan hasil tangkapan maksimum lestari ( $\left.\mathrm{h}_{\mathrm{MSY}}\right)$ dan upaya optimum ( $\left.\mathrm{E}_{\mathrm{MSY}}\right)$ pada model Schaefer adalah sebagai berikut :

$$
\begin{aligned}
& h_{M S Y}=a^{2} / 4 b \\
& E_{M S Y}=a / 2 b
\end{aligned}
$$

3. Pendugaan hasil tangkapan maksimum lestari ( $\mathrm{h}_{\mathrm{MSY}}$ ) dan upaya optimum ( $\left.\mathrm{E}_{\mathrm{MSY}}\right)$ pada model Fox adalah sebagai berikut :

$$
\begin{aligned}
h_{M S Y} & =-(1 / b) \exp ^{(a-1)} \\
E_{M S Y} & =-1 / b
\end{aligned}
$$

Keterangan :

$\mathrm{CPUE}=$ rata-rata hasil tangkapan per satuan upaya penangkapan (kg/trip)

$\mathrm{h}=$ jumlah hasil tangkapan (kg)

$\mathrm{E} \quad=$ upaya penangkapan (trip) yang sudah distandarisasi

$\mathrm{a}$ dan $\mathrm{b}=$ parameter regresi
Pengelolaan sumberdaya ikan kakap putih dengan tingkat upaya maksimum lestari dengan memaksimumkan keuntungan secara ekonomi, dianalisis dengan pendekatan model biologi dari Schaefer (1957), dan model ekonomi dari Gordon (1954), dengan rumus berikut :

$$
\pi=a p E-b p E^{2}-c E
$$

Tingkat keuntungan maksimum atau maximum economic sustainable yield (MEY) dicapai pada saat $\mathrm{d} \pi / \mathrm{dE}=0$, sehingga :

$$
M E Y=d \pi / d E=a p-2 b p E-c
$$

Tingkat upaya pada open access ( $\left.\mathrm{E}_{\mathrm{OA}}\right)$, terjadi pada saat keseimbangan bioekonomi $\pi=0$, yang secara matematis dapat dinyatakan sebagai berikut :

$$
\begin{aligned}
& \pi=T R-T C=0 \\
& a p E-b p E^{2}-c E=0 \\
& a p-b p E-c=0 \\
& E_{O A}=(a p-c) / b p
\end{aligned}
$$

Keterangan :

$$
\begin{aligned}
& \pi=\text { keuntungan dari upaya } \\
& \text { pemanfaatan sumberdaya } \\
& \mathrm{C}=\text { biaya operasional penangkapan } \\
& \text { ikan per satuan upaya } \\
& \mathrm{E}=\begin{array}{l}
\text { upaya penangkapan (trip per } \\
\text { tahun) }
\end{array} \\
& \mathrm{p}=\text { harga hasil tangkapan } \\
& \mathrm{a} \text { dan } \mathrm{b}=\text { koefisien upaya penangkapan } \\
& \mathrm{TR}=\text { total revenue (penerimaan total) } \\
& \mathrm{TC}=\text { total cost (penerimaan total) }
\end{aligned}
$$

\section{(2) Penentuan teknologi penangkapan ikan kakap putih yang tepat guna}

Penentuan teknologi penangkapan tepat guna dimaksudkan untuk mendapatkan jenis alat tangkap yang mempunyai keragaan terbaik ditinjau dari aspek biologi, teknik, sosial dan ekonomi. Kriteria penilaian yang dibangun dalam penelitian ini adalah : (1) secara biologi tidak mengganggu/merusak kelestarian sumberdaya ikan, (2) secara teknis efisien digunakan, (3) secara sosial dapat diterima masyarakat, (4) secara ekonomi menguntungkan. Penilaian terhadap kriteria yang bernilai kualitatif dilakukan secara subyektif dengan memberikan skor, sedangkan pada kriteria yang bernilai kuantitatif tidak dilakukan skroring melainkan berdasarkan nilai 
obyektif yang diperoleh di lapangan, dan urutan prioritas berdasarkan nilai tertinggi (Haluan \& Nurani, 1988).

Penilaian kriteria aspek biologi dan teknis dilakukan secara obyektif berdasarkan data lapangan. Aspek biologi yang dinilai berhubungan dengan efektifitas dan selektifitas alat tangkap, yaitu ukuran panjang (size) ikan yang tertangkap (cm/ekor), dan jumlah hasil tangkapan (kg). Aspek teknis yang dinilai berhubungan dengan efisiensi pengoperasian alat tangkap, yaitu produksi per trip $(\mathrm{kg} /$ trip), dan produksi per tenaga kerja (kg/trip/tenaga kerja).

Aspek sosial yang dinilai berhubungan dengan respon penerimaan masyarakat terhadap alat tangkap, dan penyerapan tenaga kerja (orang/trip). Respon penerimaan nelayan terhadap alat tangkap dievaluasi secara subyektif dengan memberikan skor 1 bila alat tangkap kurang disukai, skor 3 bila alat tangkap disukai, dan skor 5 bila alat tangkap sangat disukai nelayan.

Aspek ekonomi dinilai secara obyektif melalui hasil perhitungan kelayakan usaha jaring insang dan pancing ulur. Kriteria yang dinilai adalah net present value (NPV), benefit cost ratio $($ Net $\mathrm{B} / \mathrm{C})$, internal rate of return (IRR), dan pendapatan nelayan. Perhitungan kelayakan usaha (NPV, B/C, dan IRR) mengikuti prosedur yang disampaikan Husnan (1994).

Kriteria NPV digunakan untuk menilai manfaat investasi dengan rumus:

$$
N P V=\sum_{t=1}^{n} \frac{B_{t}-C_{1}}{(1+i)^{t}}
$$

\section{Keterangan :}

$$
\begin{aligned}
\mathrm{Bt} & =\text { benefit pada tahun } \mathrm{t} \\
\mathrm{Ct} & =\text { cost pada tahun } \mathrm{t} \\
\mathrm{n} & =\text { umur ekonomis dari pada proyek } \\
\mathrm{i} & =\text { discount rate (suku bunga) } \\
\mathrm{t} & =\text { periode. }
\end{aligned}
$$

Apabila NPV > 0 berarti investasi dinyatakan menguntungkan, dan apabila NPV $<0$ berarti investasi dinyatakan tidak menguntungkan (tidak layak). Apabila NPV $=0$, investasi hanya mengembalikan manfaat pada posisi sama dengan tingkat social opportunity cost of capital.

Kriteria net B/C, merupakan perbandingan antara nilai total dari manfaat bersih dengan present value total, dan dinyatakan dengan rumus :

$$
N e t B / C=\frac{\sum_{t=1}^{n} \frac{B_{t}-C_{t}}{(1+i)^{t}}[B t-C t>0]}{\sum_{t=1}^{n} \frac{B_{t}-C_{t}}{(1-i)^{t}}[B t-C t<0]}
$$

Keterangan :

$\mathrm{B}=$ keuntungan

$\mathrm{C}=$ biaya

$\mathrm{i}=$ discount rate

$\mathrm{t}=$ periode

Jika Net $\mathrm{B} / \mathrm{C}>1$, investasi layak (menguntungkan); jika Net $\mathrm{B} / \mathrm{C}=1$, usaha tidak memberikan keuntungan tetapi juga tidak rugi; dan jika Net $\mathrm{B} / \mathrm{C}<1$, investasi tidak layak (rugi).

Kriteria IRR, dapat juga dianggap sebagai tingkat keuntungan atas investasi bersih dalam suatu proyek. Setiap benefit bersih yang diwujudkan secara otomatis ditanam kembali dalam tahun berikutnya dan mendapatkan tingkat keuntungan yang diberi bunga selama sisa umur proyek. Rumus untuk menghitung IRR adalah :

$$
I R R=i_{1}+\frac{N P V^{+}}{N P V^{+}-N P V^{-}}\left(i_{2}-i_{1}\right)
$$

Keterangan:

$\mathrm{i}_{1}=$ discount rate NPV positif

$\mathrm{i}_{2}=$ discount rate NPV negatif

Bila IRR > dari tingkat bunga berlaku, berarti proyek dinyatakan layak. Bila IRR sama dengan tingkat bunga yang berlaku, maka NPV dari proyek tersebut sama dengan nol. Jika IRR < dari tingkat bunga yang berlaku, berarti proyek tidak layak.

Untuk menilai semua aspek biologi, teknis, sosial, dan ekonomi dilakukan standardisasi sehingga semua nilai mempunyai standar yang sama. Standardisasi menggunakan metode fungsi nilai, dengan rumus (Mangkusubroto \& Trisnadi, 1987) :

$$
\begin{gathered}
v(x): \frac{x-x_{0}}{x_{1}-x_{0}} \\
v(A)=\sum_{i=1}^{i=n} v_{i}\left(x_{i}\right)
\end{gathered}
$$

Keterangan :

$\mathrm{V}(\mathrm{X}) \quad=$ fungsi nilai dari variabel $\mathrm{X}$

$\mathrm{X}_{1} \quad=$ nilai tertinggi pada kriteria $\mathrm{X}$

$\mathrm{X}_{0} \quad=$ nilai terendah pada kriteria $\mathrm{X}$

$\mathrm{V}(\mathrm{A}) \quad=$ fungsi nilai dari alternatif $\mathrm{A}$

$\mathrm{V}_{\mathrm{i}}\left(\mathrm{X}_{\mathrm{i}}\right)=$ fungsi nilai dari alternatif pada kriteria i, i $=1,2,3, \ldots$. 
(3) Strategi kebijakan pengembangan perikanan kakap putih

Analisis strategi pengembangan perikanan kakap putih dilakukan dengan menggunakan pendekatan analitycal hierarchy process (AHP) (Saaty, 1991). Penyusunan hirarki diawali dengan menentukan tujuan umum yang berada pada level 1, pihakpihak yang berkepentingan di level 2, faktor-faktor pengembangan di level 3 , tujuan yang ingin dicapai di level 4 , dan alternatif strategi kebijakan pengembangan di level terakhir. Selanjutnya alternatif strategi pengembangan dirancang interaksinya satu sama lain dengan bentuk struktur hirarki dengan memperhatikan pelaku utama, kriteria pengembangan, dan tujuan pengembangan.

\section{HASIL DAN PEMBAHASAN}

\subsection{Hasil Penelitian}

\subsubsection{Model Bio-Ekonomi Perikanan} Kakap Putih di Kabupaten Mimika

Model Schaefer lebih tepat diaplikasikan dalam pendugaan potensi ikan kakap putih di perairan Kabupaten Mimika dibandingkan dengan model fox, karena nilai koefisien determinasi $\left(R^{2}\right)$ model schaefer lebih besar. Hasil tangkapan maksimum lestari ( $\left.\mathrm{h}_{\mathrm{MSY}}\right)$ untuk kakap putih adalah 8.348 ton/tahun, dan effort optimum pada tingkat potensi maksimum lestari ( $\left.\mathrm{E}_{\mathrm{MSY}}\right)$
970.122 trip/tahun (Gambar 1).

Berdasarkan model bio-ekonomi (Gambar 2), peningkatan upaya penangkapan diikuti produksi dan penerimaan yang meningkat hingga pada kondisi MSY dengan penerimaan usaha tertinggi pada kondisi MEY. Peningkatan upaya penangkapan juga diiringi dengan peningkatan biaya penangkapan. Rente ekonomi terbesar diperoleh pada kondisi pengelolaan MEY yaitu Rp 56,91 milyar/tahun. Rente ekonomi pada kondisi MEY ini tercapai pada saat produksi $\left(\mathrm{h}_{\mathrm{MEY}}\right) \quad 8.094$ ton/tahun sehingga menghasilkan total penerimaan (TRMEY) Rp 80,94 milyar/tahun dikurangi total biaya ( $\left.\mathrm{TC}_{\mathrm{MEY}}\right) \quad \mathrm{Rp} 24,03$ milyar/tahun.

Perbandingan produksi, effort, penerimaan, biaya, dan rente ekonomi pada berbagai kondisi pengelolaan, yaitu pada kondisi aktual, maximum sustainable yield (MSY), maximum economic yield (MEY) dan open access (OA) disajikan pada Tabel 1. Produksi dan upaya penangkapan kakap putih di Kabupaten Mimika dewasa ini masih jauh di bawah batasan keseimbangan bio-ekonomi. Kondisi tersebut merupakan indikasi bahwa peluang pengembangan produksi dan upaya penangkapan kakap putih masih besar hingga pada kondisi pengelolaan MSY dan MEY. Pada kondisi pengelolaan di tingkat MSY, produksi dan effort masih dapat ditingkatkan masing-masing

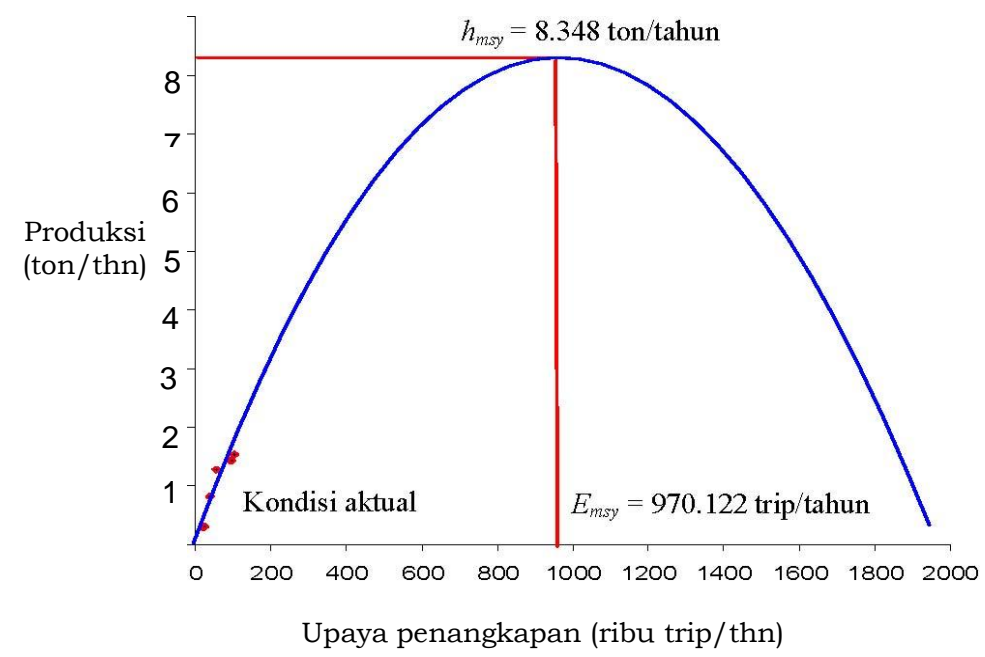

Gambar 1. Hubungan antara produksi dengan upaya penangkapan, dugaan potensi lestari dan upaya penangkapan optimum dalam perikanan kakap putih di perairan Mimika 
sebesar 81,54\% dan 89,31\% dari kondisi aktual. Pada pengelolaan di tingkat MEY, peningkatan produksi dan effort perikanan kakap putih masing-masing sebesar 80,96\% dan 87,06\% dari kondisi actual (Tabel 2).

\subsubsection{Eksplorasi teknologi kapan ikan tepat guna}

penang-

Prioritas teknologi tepat guna dalam penangkapan kakap putih dievaluasi dengan menggunakan kriteria aspek biologi, teknis, sosial dan ekonomi. Berdasarkan penilaian kriteria aspek biologi yang meliputi ukuran ikan kakap $\left(\mathrm{X}_{1}\right)$, dan persentase jumlah tangkapan ikan target $\left(\mathrm{X}_{2}\right)$, maka pengembangan pancing ulur lebih diprioritaskan dibandingkan dengan jaring insang (Tabel 3). Akan tetapi berdasarkan penilaian aspek teknis dengan kriteria produksi per trip $\left(\mathrm{X}_{1}\right)$, dan produksi per trip per tenaga kerja $\left(\mathrm{X}_{2}\right)$, maka jaring insang lebih diprioritaskan pengembangannya dibandingkan dengan pancing ulur (Tabel 4).

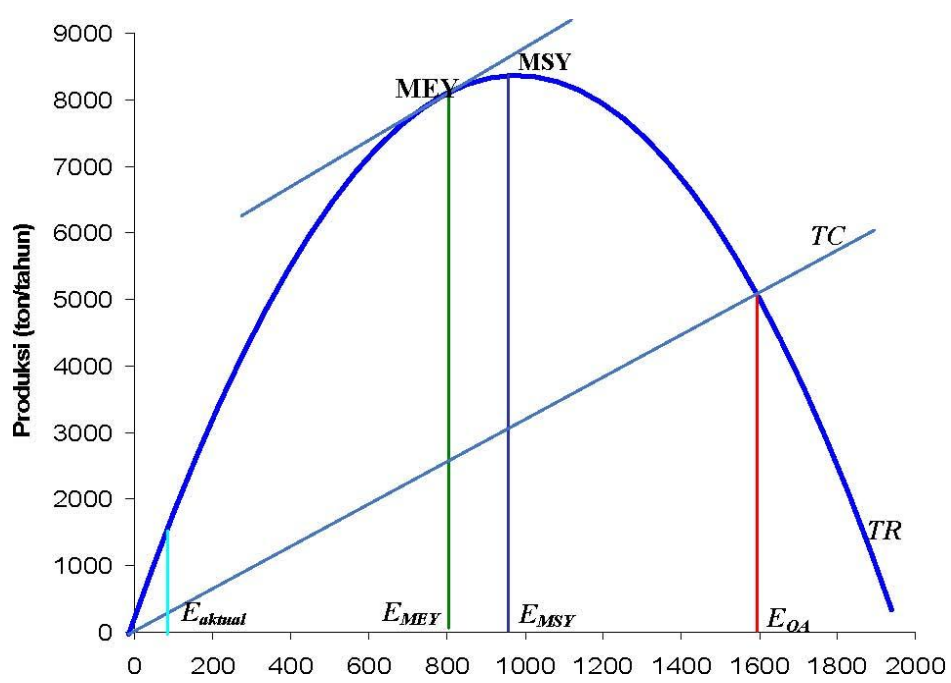

Gambar 2. Model bio-ekonomi untuk pengelolaan perikanan kakap putih di perairan Mimika

Tabel 1. Status pengelolaan sumberdaya ikan kakap putih di perairan Mimika, tahun 2005

\begin{tabular}{|c|ccccc|}
\hline $\begin{array}{c}\text { Kondisi } \\
\text { pengelolaan }\end{array}$ & $\begin{array}{c}\text { Produksi } \\
\text { (Ton) }\end{array}$ & Effort (Trip) & $\begin{array}{c}\text { Total } \\
\text { Penerimaan } \\
\text { (Rp.milyar) }\end{array}$ & $\begin{array}{c}\text { Total Biaya } \\
\text { (Rp.milyar) }\end{array}$ & $\begin{array}{c}\text { Rente } \\
\text { Ekonomi } \\
\text { (Rp.milyar) }\end{array}$ \\
\hline Aktual & 1.541 & 103.669 & 15,41 & 3,11 & 12,30 \\
MEY & 8.094 & 801.013 & 80,94 & 24,03 & 56,91 \\
MSY & 8.348 & 970.122 & 83,48 & 29,10 & 54,38 \\
OA & 4.806 & 1.602 .025 & 48,06 & 48,06 & 0 \\
\hline
\end{tabular}

Tabel 2. Peluang pengembangan perikanan kakap putih pada kondisi pengelolaan MSY, dan MEY di Kabupaten Mimika

\begin{tabular}{|l|cc|cc|}
\hline Kondisi & \multirow{2}{*}{$\begin{array}{c}\text { Effort } \\
\text { pengelolaan }\end{array}$} & Produksi & \multicolumn{2}{|c|}{ Peluang pengembangan(\%) } \\
\cline { 4 - 5 } (trip/tahun) & (ton/tahun) & \multicolumn{2}{|c|}{ Effort } & Produksi \\
\hline Aktual & 103.669 & 1.541 & & \\
MSY & 970.112 & 8.348 & 89,31 & 81,54 \\
MEY & 801.013 & 8.094 & 87,06 & 80,96 \\
\hline
\end{tabular}


Tabel 3. Penilaian aspek biologi untuk menentukan teknologi penangkapan kakap putih yang tepat guna di perairan Mimika

\begin{tabular}{|l|cccc|cccc|}
\hline \multirow{2}{*}{ Jenis teknologi } & \multicolumn{4}{|c|}{ Kriteria } & \multicolumn{5}{c|}{ Hasil Standarisasi Terhadap Kriteria } \\
\cline { 2 - 9 } & $\mathrm{X}_{1}$ & $\mathrm{UP}_{1}$ & $\mathrm{X}_{2}$ & $\mathrm{UP}_{2}$ & $\mathrm{~V}_{1}\left(\mathrm{X}_{1}\right)$ & $\mathrm{V}_{2}\left(\mathrm{X}_{2}\right)$ & Total & $\mathrm{UP}$ \\
\hline Jaring insang & 4,5 & $\mathrm{II}$ & 40 & $\mathrm{II}$ & 0 & 0 & 0 & II \\
Pancing ulur & 6 & $\mathrm{I}$ & 70 & $\mathrm{I}$ & 1 & 1 & 2 & $\mathrm{I}$ \\
\hline
\end{tabular}

Keterangan : UP $=$ urutan prioritas

Tabel 4. Penilaian aspek teknis untuk menentukan teknologi penangkapan kakap putih yang tepat guna di perairan Mimika

\begin{tabular}{|l|cccc|cccc|}
\hline Jenis teknologi & \multicolumn{4}{|c|}{ Kriteria } & \multicolumn{4}{|c|}{ asil Standarisasi Terhadap Kriteria } \\
\cline { 2 - 9 } & $\mathrm{X}_{1}$ & $\mathrm{UP}_{1}$ & $\mathrm{X}_{2}$ & $\mathrm{UP}_{2}$ & $\mathrm{~V}_{1}\left(\mathrm{X}_{1}\right)$ & $\mathrm{V}_{2}\left(\mathrm{X}_{2}\right)$ & Total & UP \\
\hline Jaring insang & 60 & $\mathrm{I}$ & 20 & $\mathrm{I}$ & 1 & 1 & 2 & $\mathrm{I}$ \\
Pancing ulur & 40 & $\mathrm{II}$ & 13 & $\mathrm{II}$ & 0 & 0 & 0 & II \\
\hline
\end{tabular}

Keterangan : UP $=$ urutan prioritas

Hasil penilaian aspek sosial dengan menggunakan kriteria penyerapan jumlah tenaga kerja tiap unit penangkapan $\left(\mathrm{X}_{1}\right)$, dan tingkat penerimaan masyarakat nelayan terhadap jenis teknologi yang digunakan $\left(\mathrm{X}_{2}\right)$, menunjukkan bahwa masyarakat nelayan lebih menginginkan (menyukai) untuk memiliki alat tangkap jaring insang dibandingkan pancing ulur (Tabel $5)$.

Kriteria yang digunakan dalam penilaian aspek ekonomi adalah kelayakan financial (NPV, B/C, IRR), dan pendapatan nelayan. Berdasarkan analisis kelayakan finansial, jaring insang dan pancing ulur layak dikembangkan dalam usaha penangkapan kakap putih di perairan Mimika (Tabel 6). Berdasarkan nilai B/C, setiap biaya $\mathrm{Rp}$ 1,00 yang dikeluarkan pada jaring insang akan diperoleh keuntungan $\mathrm{Rp} 1,93$, sedangkan pada pancing ulur hanya $\mathrm{Rp} 1,79$. Artinya bahwa jaring insang lebih menguntungkan dibandingkan pancing ulur dalam usaha penangkapan kakap putih. Indikasi besarnya keuntungan tersebut juga diperkuat oleh nilai NPV dari jaring insang yang lebih besar daripada pancing ulur. Nilai IRR untuk usaha jaring insang sebesar $43,99 \%$ dan untuk pancing ulur sebesar 40,98\%. Hal ini berarti bahwa nilai IRR dari kedua jenis alat tangkap yang dikaji berada di atas discount rate $18 \%$. Hasil penilaian aspek ekonomi dengan kriteria NPV $\left(\mathrm{X}_{1}\right)$, Net $B / C\left(X_{2}\right)$, IRR $\left(X_{3}\right)$, dan pendapatan nelayan $\left(\mathrm{X}_{4}\right)$ menunjukkan bahwa jaring insang lebih diprioritaskan pengembangannya dibandingkan dengan pancing ulur (Tabel 7).

Berdasarkan hasil analisis terhadap aspek teknis, sosial dan ekonomi, jaring insang memiliki keragaan yang lebih baik dibandingkan pancing ulur. Namun dari aspek biologi, ternyata pancing ulur memiliki keragaan yang lebih baik dibandingkan jaring insang. Setelah dilakukan penggabungan keempat aspek biologis, teknis, sosial dan ekonomi (Tabel 8), dapat disimpulkan bahwa teknologi penangkapan tepat guna yang lebih diprioritaskan pengembangannya dalam penangkapan kakap putih di perairan Mimika adalah aring insang. 
Tabel 5. Penilaian aspek sosial untuk menentukan teknologi penangkapan kakap putih yang tepat guna di perairan Mimika

\begin{tabular}{|l|cccc|cccc|}
\hline \multirow{2}{*}{ Jenis teknologi } & \multicolumn{4}{|c|}{ Kriteria } & \multicolumn{4}{c|}{ Hasil Standarisasi Terhadap Kriteria } \\
\cline { 2 - 9 } & $\mathrm{X}_{1}$ & $\mathrm{UP}_{1}$ & $\mathrm{X}_{2}$ & $\mathrm{UP}_{2}$ & $\mathrm{~V}_{1}\left(\mathrm{X}_{1}\right)$ & $\mathrm{V}_{2}\left(\mathrm{X}_{2}\right)$ & Total & $\mathrm{UP}$ \\
\hline Jaring insang & 3 & $\mathrm{I}$ & 5 & $\mathrm{I}$ & 1 & 1 & 2 & $\mathrm{I}$ \\
Pancing ulur & 3 & $\mathrm{I}$ & 3 & $\mathrm{II}$ & 1 & 0 & 1 & $\mathrm{II}$ \\
\hline
\end{tabular}

Keterangan : UP $=$ urutan prioritas

Tabel 6. Nilai NPV, B/C, dan IRR jaring insang dan pancing ulur dalam pemanfaatan ikan kakap putih di perairan Mimika

\begin{tabular}{|l|cc|}
\hline \multirow{2}{*}{ Kriteria investasi } & \multicolumn{2}{|c|}{ Usaha penangkapan ikan kakap putih } \\
\cline { 2 - 3 } & Jaring insang & Pancing ulur \\
\hline NPV (Rp 1 juta) & 26,26 & 16,88 \\
Net B / C & 1,93 & 1,79 \\
IRR (\%) & 43,99 & 40,98 \\
\hline
\end{tabular}

Tabel 7. Penilaian aspek ekonomi untuk menentukan teknologi penangkapan kakap putih yang tepat guna di perairan Mimika

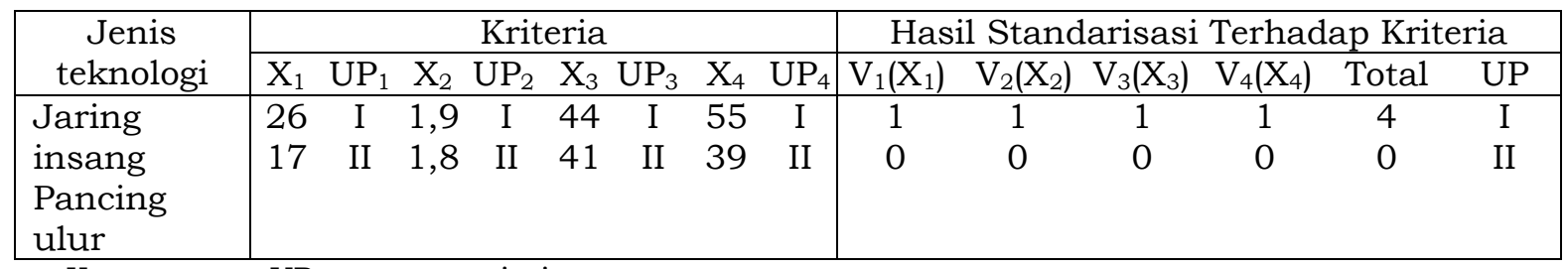

Keterangan : UP $=$ urutan prioritas

Tabel 8. Penilaian aspek biologi, teknis, sosial, dan ekonomi untuk menentukan teknologi penangkapan kakap putih yang tepat guna di perairan Mimika

\begin{tabular}{|c|c|c|c|c|c|c|c|c|c|c|}
\hline \multirow{2}{*}{$\begin{array}{l}\text { Jenis } \\
\text { teknologi }\end{array}$} & \multicolumn{4}{|c|}{ Aspek } & \multicolumn{6}{|c|}{ Hasil Standarisasi Terhadap Aspek } \\
\hline & $\begin{array}{c}\text { Biologi } \\
\left(\mathrm{X}_{1}\right)\end{array}$ & $\begin{array}{l}\text { Teknis } \\
\left(\mathrm{X}_{2}\right)\end{array}$ & $\begin{array}{c}\text { Sosial } \\
\left(\mathrm{X}_{3}\right)\end{array}$ & $\begin{array}{c}\text { Ekonom } \\
\mathrm{i}\left(\mathrm{X}_{4}\right)\end{array}$ & $\mathrm{V}_{1}\left(\mathrm{X}_{1}\right)$ & $\mathrm{V}_{2}\left(\mathrm{X}_{2}\right)$ & $\mathrm{V}_{3}\left(\mathrm{X}_{3}\right)$ & $\mathrm{V}_{4}\left(\mathrm{X}_{4}\right)$ & Total & UP \\
\hline Jaring & 0 & 2 & 2 & 4 & 0 & 1 & 1 & 1 & 3 & I \\
\hline $\begin{array}{l}\text { insang } \\
\text { Pancing ulur }\end{array}$ & 2 & 0 & 1 & 0 & 1 & 0 & 0 & 0 & 1 & II \\
\hline
\end{tabular}

Keterangan : UP $=$ urutan prioritas

\subsection{Pembahasan}

Potensi lestari ikan kakap putih di perairan Kabupaten Mimika diperkirakan 8.348 ton/tahun. Hasil tangkapan kakap putih di perairan Mimika tersebar di tiga habitat, yaitu di sekitar perairan pantai, muara sungai hingga ke hulu sungai. Kondisi perairan Mimika cocok dengan habitat yang dikehendaki ikan kakap putih, karena banyaknya sungai yang bermuara, dan didukung juga oleh kondisi mangrove yang masih baik. Menurut Simbolon (2008), kondisi perairan yang sesuai dengan habitat yang dikehendaki oleh ikan akan berpengaruh terhadap siklus hidup dan recruitment ikan, dan akibatnya akan berdampak positif terhadap besarnya potensi ikan.

Menurut Azis (1989) diacu dalam Muksin (2006), tingkat pemanfaatan sumberdaya ikan dikelompokkan menjadi tiga kategori yaitu : (1) under exploited dengan tingkat pemanfaatan $\leq$ $65 \%$, (2) optimal dengan tingkat pemanfaatan $>65 \%$ dan $<100 \%$, (3) overfishing dengan tingkat pemanfaatan $\geq 100 \%$. Berdasarkan pengelompokan tersebut, maka tingkat pemanfaatan kakap putih di perairan Kabupaten 18 
Mimika pada tahun 2005 termasuk dalam kategori under exploited, yaitu sekitar 19\%. Dengan demikian, upaya penangkapan masih dapat ditambah hingga mencapai batasan keseimbangan secara bio-ekonomi dalam rangka meningkatkan hasil tangkapan.

Tingkat pemanfaatan yang masih dalam kategori under exploited, membuka peluang bagi nelayan untuk lebih mengintensifkan kegiatan penangkapan kakap putih di perairan Kabupaten Mimika. Dari pengamatan di lapangan, kendala utama yang menyebabkan rendahnya tingkat pemanfaatan kakap putih karena jarring insang dan pancing ulur masih menggunakan perahu tanpa motor, dan rantai pemasaran belum tertata dengan baik.

Pemanfaatan sumberdaya kakap putih diharapkan dapat memberikan manfaat yang lebih luas, baik untuk peningkatan kesejahteraan nelayan, sumber penerimaan daerah, dan peningkatan konsumsi ikan. Oleh karena itu potensi sumberdaya kakap putih di Kabupaten Mimika sudah seharusnya dimanfaatkan sebesar-besarnya dengan tetap menjaga kelestarian sumberdaya. Malanesia et al. (2007), menyatakan bahwa kelestarian sumberdaya ikan dapat terjaga bilamana regulasi dalam pengelolaannya dapat dijalankan dengan baik oleh para pelaku perikanan, termasuk kebijakan yang tepat untuk menentukan jenis teknologi tepat guna, serta jumlah alokasi optimum unit penangkapan ikan.

Pemanfaatan kakap putih pada tahun 2005 baru mencapai 1.541 ton dengan rata-rata 1.303 ton/tahun selama periode 1999-2005. Hal tersebut menunjukkan bahwa tingkat pemanfaatan masih jauh dari yang diharapkan bila dibandingkan pada tingkat MEY (8.094 ton/tahun) dan MSY (8.348 ton/tahun). Harahap et al. (2006) menyatakan bahwa potensi sumberdaya ikan yang belum termanfaatkan hingga pada kondisi maximum economic yield (MEY) sebenarnya merupakan suatu kerugian karena belum dapat mengoptimalkan rente ekonomi secara optimal.

Rente ekonomi secara perlahan semakin berkurang dengan meningkatnya total biaya (TC) akibat dari penambahan effort, sementara total penerimaan (TR) semakin berkurang akibat terjadinya penurunan produksi. Penambahan effort hingga pada kondisi MSY menghasilkan penurunan rente ekonomi menjadi sebesar Rp 54,38 milyar/tahun. Penambahan effort yang tidak terkendali hingga mencapai kondisi keseimbangan open access ( $\left.\mathrm{E}_{\mathrm{OA}}\right)$, menyebabkan total penerimaan (TR) sama dengan total biaya (TC), sehingga tidak ada lagi rente ekonomi yang diterima (nol). Gordon, (1954) menyebutkan bahwa tingkat effort pada kondisi open access $\left(\mathrm{E}_{\mathrm{OA}}\right)$ disebut sebagai bioeconomic equilibrium of open access fishery. Pada kondisi pengelolaan open access nelayan cenderung menambah upaya penangkapannya secara besarbesaran dengan harapan akan mendapatkan hasil tangkapan yang lebih besar, dan kondisi ini dapat berdampak negatif terhadap kelestarian SDI.

Peningkatan produksi kakap putih di perairan Mimika seyogianya tidak semata-mata hanya untuk mencari keuntungan secara ekonomi saja, tetapi juga harus memperhatikan daya dukung dari sumberdaya ikan. Hal ini berarti bahwa pemanfaatan kakap putih di perairan Mimika disarankan dilakukan hanya sampai pada titik MEY karena pada kondisi ini akan diperoleh keuntungan ekonomi bagi para pelaku perikanan, tanpa mengganggu kelestarian sumberdaya kakap putih itu sendiri (keuntungan biologi). Menurut Simbolon \& Mustaruddin (2006), usaha perikanan tangkap seyogianya tidak hanya berorientasi terhadap permintaan pasar semata tetapi juga harus mempertimbangkan daya dukung sumberdaya ikan agar tetap dijaga kelestariannya, sehingga dapat menjamin keberlanjutan usaha.

Berdasarkan penilaian aspek biologis, pengembangan pancing ulur lebih diprioritaskan dibandingkan dengan jaring insang, karena kakap putih yang tertangkap dengan pancing ulur memiliki ukuran lebih besar (ratarata $6 \mathrm{~kg} /$ ekor) dibandingkan dengan jaring insang (rata-rata 4,5 kg/ekor). Disamping itu, pancing ulur lebih selektif dalam menghasilkan kakap putih (target species) dibandingkan jaring insang karena persentase tangkapan target species pada pancing ulur sebesar $70 \%$, sedangkan pada jaring insang hanya $40 \%$. Namun demikian, jaring insang 
lebih produktif daripada pancing ulur. Hal ini sesuai dengan pendapat Monintja (1987), bahwa pancing umumnya memiliki tingkat selektivitas yang tinggi, namun kemampuan tangkapnya (catchability) relatif rendah dibandingkan dengan jaring insang.

Berdasarkan evaluasi aspek sosial, nelayan Mimika lebih menyukai jaring insang dibandingkan dengan pancing ulur, walaupun kedua alat tangkap ini memiliki daya serap tenaga kerja yang sama. Hasil wawancara dengan masyarakat menunjukkan bahwa status sosial nelayan akan lebih baik jika mereka dapat memiliki unit penangkapan jaring insang.

Strategi pengembangan perikanan kakap putih di Kabupaten Mimika ditentukan berdasarkan harapan para stakeholder (aktor), dengan mempertimbangkan faktor-faktor berpengaruh (kriteria) dan tujuan pengembangan. Aktor, faktor, dan tujuan tersebut disusun dalam bentuk hirarki melalui analisis AHP. Penggunaan AHP didasari atas pertimbangan bahwa AHP merupakan metode yang sederhana dan fleksibel yang menampung kreativitas dan rancangannya terhadap suatu masalah (Saaty, 1991). Rasio kepentingan yang menunjukkan prioritas masing-masing komponen yang terdapat pada aktor, faktor (kriteria), tujuan, dan alternatif strategi pengembangan dapat dilihat pada Gambar 3.

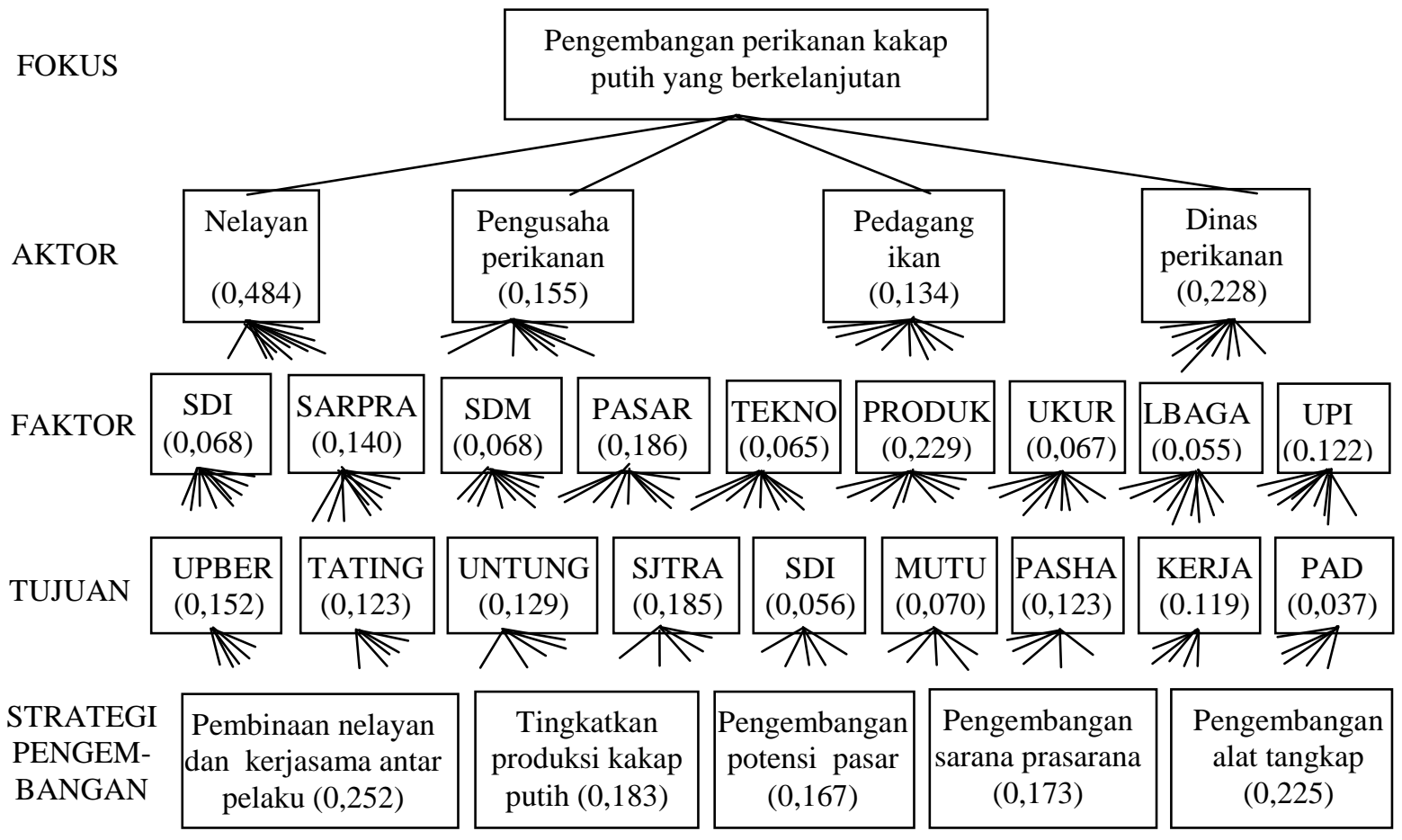

Gambar 3. Hirarki pengembangan perikanan kakap putih di Kabupaten Mimika

Aktor yang berperan dalam pengembangan perikanan kakap putih di Kabupaten Mimika adalah nelayan, pengusaha perikanan, pedagang ikan, dan Dinas Perikanan. Nelayan mendapat prioritas tertinggi dengan rasio kepentingan 0,484 , sedangkan prioritas terakhir adalah pedagang ikan. Nelayan memiliki rasio kepentingan paling besar karena nelayan dianggap sebagai ujung tombak paling berperan memberikan kontribusi dalam pemanfaatan dan penyediaan pasokan kakap putih di
Kabupaten Mimika. Simbolon \& Mustaruddin (2006) juga melaporkan bahwa nelayan merupakan pelaku utama yang paling diprioritaskan dalam pengembangan perikanan cakalang di perairan Sorong.

Pedagang pengumpul ikan belum mendapat prioritas penting dalam pengembangan perikanan kakap putih di Kabupaten Mimika. Hal ini mungkin disebabkan karena pedagang ikan selama ini belum mendistribusikan produksi kakap putih ke luar daerah 
Mimika, akan tetapi lebih mengutamakan distribusinya untuk konsumsi lokal dalam produk ikan segar.

Faktor-faktor yang berpengaruh dalam pengembangan perikanan kakap putih di Kabupaten Mimika adalah potensi sumberdaya ikan (SDI), sarana dan prasarana (SARPRA), potensi sumberdaya manusia (SDM), peluang pasar (PASAR), adopsi teknologi (TEKNO), ukuran ikan tangkapan (UKUR), produksi hasil tangkapan (PRODUK), kelembagaan (LBAGA), dan unit penangkapan ikan (UPI). Faktor pengembangan perikanan kakap putih yang utama adalah produksi hasil tangkapan dengan rasio kepentingan 0,229, dan terakhir adalah unit penangkapan dengan rasio kepentingan 0,122. Stakeholders perikanan kakap putih di Kabupaten Mimika lebih mementingkan produksi hasil tangkapan yang tinggi karena mereka menganggap bahwa produksi kakap putih merupakan faktor yang paling menentukan dalam keberlanjutan usaha, dan akan meningkatkan pendapatan keluarga nelayan. Malanesia et al. (2008) melaporkan bahwa faktor pembatas yang paling menentukan keberhasilan pengembangan perikanan pelagis di Lampung Selatan adalah ketersediaan SDM yang terampil. Perbedaan ini mungkin saja disebabkan karena kondisi dan karakteristik perikanan pelagis dan perikanan kakap putih yang berbeda.

Faktor keterampilan nelayan (SDM) dalam kegiatan penangkapan kakap putih di perairan Mimika belum mendapat prioritas penting karena para stakeholders menganggap potensi ikan masih banyak dan belum ditemukan kesulitan untuk menangkap ikan walaupun hanya menggunakan teknologi sederhana. Akibatnya, faktor potensi SDI, ukuran ikan, dan adopsi teknologi belum mendapat prioritas penting.

Tujuan yang diharapkan dalam perikanan kakap putih adalah usaha penangkapan berkelanjutan (UPBER), hasil tangkapan tinggi (TATING), keuntungan usaha maksimal (UNTUNG), kesejahteraan nelayan meningkat (SJTRA), potensi SDI lestari (SDI), mutu ikan baik (MUTU), pemasaran dan harga terjamin (PASHA), lapangan kerja meningkat (KERJA), pendapatan asli daerah meningkat (PAD). Tujuan pengembangan perikanan kakap putih yang menjadi prioritas utama adalah kesejahteraan nelayan dengan rasio kepentingan 0,185, dan prioritas terakhir adalah pemasaran dan harga terjamin dengan rasio kepentingan 1,23.

Tingginya nilai rasio kepentingan terhadap kesejahteraan nelayan merupakan indikasi bahwa para stakeholders memberikan tanggapan positif akan pentingnya peranan nelayan sebagai ujung tombak dalam pemanfaatan dan penyediaan pasokan kakap putih di Kabupaten Mimika. Hal ini sesuai dengan pendapat Simbolon (2008), yang menyatakan bahwa upaya untuk menuju perikanan berkelanjutan adalah usaha penangkapan menguntungkan agar kesejahteraan nelayan terpenuhi, pengoperasian teknologi penangkapan tepat guna, alokasi unit penangkapan dan sumberdaya ikan yang optimum.

Upaya untuk menjaga potensi SDI agar tetap lestari belum menjadi prioritas tujuan karena para stakeholders beranggapan bahwa potensi ikan kakap putih di peraran Mimika masih cukup tinggi, bahkan tingkat pemanfaatannya masih rendah. Upaya untuk menghasilkan ikan yang bermutu tinggi juga dianggap belum perlu diprioritaskan karena kakap putih yang tertangkap masih terbatas pemasarannya untuk konsumsi lokal dalam bentuk produk ikan segar.

Strategi pengembangan perikanan kakap putih di Kabupaten Mimika adalah pembinaan nelayan dan kerjasama antar pelaku sebagai prioritas pertama, dan prioritas selanjutnya secara berurutan adalah pengembangan alat tangkap, peningkatan produksi, pengembangan sarana dan prasarana, dan pengembangan potensi pasar. Terpilihnya pembinaan nelayan dan kerjasama antar pelaku perikanan sebagai prioritas pertama dalam strategi pengembangan perikanan kakap putih di Kabupaten Mimika karena strategi tersebut mengakomodir dengan lebih baik para pelaku perikanan, faktorfaktor pembatas dalam pengembangan, dan tujuan pengembangan yang ditetapkan. 


\section{KESIMPULAN DAN SARAN}

\subsection{Kesimpulan}

Kesimpulan yang diperoleh dari penelitian ini adalah :

1. Potensi lestari ikan kakap putih di perairan Kabupaten Mimika diperkirakan 8.348 ton/tahun, dan tingkat keuntungan maksimum tercapai pada saat produksi sebesar 8.094 ton/tahun.

2. Untuk mencapai keuntungan maksimum dengan tetap menjamin kelestarian sumberdaya ikan, upaya penangkapan masih dapat ditingkatkan hingga $87 \%$ dari kondisi aktual atau 697.344 trip/tahun.

3. Teknologi tepat guna yang lebih diprioritaskan pengembangannya dalam penangkapan kakap putih di perairan Mimika adalah jaring insang dibandingkan dengan pancing ulur.

4. Strategi pengembangan dalam usaha penangkapan kakap putih di perairan Kabupaten Mimika lebih diprioritaskan pada aspek pembinaan nelayan, dan kerjasama antar pelaku perikanan untuk meningkatkan produksi dan kesejahteraan nelayan.

\subsection{Saran}

Saran yang dapat diberikan untuk menindaklanjuti penelitian ini adalah :

1. Pemerintah daerah perlu menyusun dan melaksanakan program-program yang berorientasi pada aspek pembinaan nelayan dan kerjasama antar pelaku perikanan.

2. Diperlukan upaya sosialisasi yang lebih intensif terutama kepada pemerintah darah dan usaha penangkapan kakap putih, terkait dengan jumlah upaya penangkapan dan hasil tangkapan kakap putih yang diperbolehkan.

3. Untuk memacu peningkatan produksi tangkapan, diperlukan kajian tentang adopsi teknologi alat tangkap baru yang lebih produktif untuk mendukung alat tangkap yang sudah ada.

\section{UCAPAN TERIMA KASIH}

Penulis mengucapkan terima kasih kepada para ABK unit penangkapan jaring insang dan pancing ulur, serta pedagang pengumpul ikan yang bersedia sebagai responden dalam penelitian ini. Penulis juga menyampaikan terimakasih kepada reviewer yang telah memberikan masukan perbaikan, sehingga dapat menambah bobot tulisan ini ke arah yang lebih baik.

\section{DAFTAR PUSTAKA}

Dinas Perikanan dan Kelautan Kab. Mimika. 2006. Statistik Perikanan. Mimika. 12 hal.

Fauzi A., dan S. Anna, 2002. Evaluasi status keberlanjutan pembangunan perikanan. Aplikasi Pendekatan Rapfish. Jurnal Jurusan Sosial Ekonomi Perikanan FPIK IPB. Bogor. Hal 43-55.

Gordon, H.S. 1954. The economic theory of a common property resources : The fishery. Journal of Political Economy. 62 : 124-142.

Husnan S. 1994. Studi kelayakan proyek. Edisi Ketiga. UPP AMP YKPN. Yogyakarta. 379 hal.

Haluan, J dan T. W. Nurani. 1988. Penerapan Metode Skoring dalam Pemilihan Tehnologi Penangkapan Ikan yang Sesuai untuk Dikembangkan di Suatu Wilayah Perairan. Bulletin Jurusan Pemanfaatan Sumberdaya Perikanan, Fakultas Perikanan. IPB Bogor. Vol. II No. 1. Hal 5-17.

Malanesia, M., J. Haluan, H. Hardjomidjojo, dan D. Simbolon. 2007. Analisis Unit Penangkapan Ikan Pilihan di Kabupaten Lampung Selatan. Buletin PSP. IPB Bogor. Vol. XVI No. 3. Hal. 483501.

Malanesia, M., J. Haluan, H. Hardjomidjojo, dan D. Simbolon. 2008. Sensitivitas Opsi Pengembangan Unit Penangkapan Ikan Terpilih di Kabupaten Lampung Selatan. Buletin PSP. IPB Bogor. Vol. XVII No. 1. Hal. 88-110.

Mangkusubroto, K. \& C.L. Trisnadi. 1987. Analisa keputusan. Pendekatan system dalam manajemen usaha dan proyek. Ganeca Exact. Bandung. 271 hal. 
Monintja, D.R. 1987. Beberapa teknologi pilihan untuk pemanfaatan sumberdaya hayati laut di Indonesia. Buletin Jurusan Pemanfaatan Sumberdaya Perikanan. Fakultas Perikanan IPB. Vol, no 1. Hal 14-25.

Saaty, T.L. 1991. Decision making for leader : The analytical hierarchy process for decision complex word. Edisi bahasa Indonesia (terjemahan Liana Setiono). PT. Pustaka Binaman Pressindo. Jakaera. 270 hal.

Schaefer, M.B. 1957. Some aspect of the dynamics of population important to the management of commercial marine fisheries. Buletin of the Inter-America Tropical Tuna Commission. 1 : 27 -56.

Simbolon, D., dan Mustaruddin. 2006. Prioritas Kebijakan Pengembangan Sistem Perikanan Cakalang di Perairan Sorong. Buletin PSP. IPB Bogor. Vol. XV No. 2. Hal. 73-85.

Simbolon D. 2008. Alokasi Unit Penangkapan Cakalang, Menuju Usaha Perikanan Berkelanjutan di Perairan Sorong. Jurnal Mangrove \& Pesisir PSPK Univ. Bung Hatta Padang. Vol. VIII No. 1. Hal. 13-21. 
